\title{
Design and Comparison of Grid Connected Permanent Magnet Synchronous Generator Non-salient Pole and Salient Pole Rotor Wind Turbine
}

\author{
S. M. Mehedi Hasan and Abu Hena MD Shatil
}

\begin{abstract}
Variable speed wind turbines are widely used wind energy conversion system (WECS). Among them doubly fed induction generator (DFIG) and permanent magnet synchronous generator (PMSG) are mostly used. PMSG based wind turbines are getting more popular in recent times because of their several advantages over other types. Direct drive capability and low speed operation are some of its significant advantages over other type. In the dq0 reference frame, this analysis discusses the implementation and simulation of a Simulink-based operated permanent magnet synchronous generator (PMSG) wind turbine. The current control subsystem makes use of PID controllers to regulate the wind turbine's velocity, direct and quadrature stator currents, and blade pitch tilt. The pitch angle controller monitors both the generator's speed and active strength, restricting both in the event of high-speed wind conditions. PMSGs exhibit constant excitation that is uncontrollable. As a result, a properly designed damper winding is needed to ensure stable operation in the absence of a frequency controller. This article analyzes and compares the performance of three-phase non-salient pole permanent magnet ac machines and salient pole machine fitted with damper windings in rigid network operation. The recommendations for network-connected generators are determined by evaluating the results of a circuit-based mathematical models of the PM-machine.
\end{abstract}

Index Terms-- Wind turbine, Variable speed, PMSG, Rotor, Salient pole, Grid.

\section{INTRODUCTION}

$\mathrm{W}$ ind energy conversion system (WECS) is designed to run at a variable speed over a large speed range in order to produce peak power at low wind speeds and at a constant speed and power output at high wind speeds. Then, the traditional synchronous generator is used to generate alternating current electricity with a variable frequency over a broad frequency spectrum. Since it is less expensive than other generators, it is also financially sustainable [1-2]. The

S. M. Mehedi Hasan is a master's student of EEE department of American International University-Bangladesh, 408/1, Kuratoli, Khilkhet, Dhaka 1229. Bangladesh. Email: smmehedi2014@gmail.com

Abu Hena MD Shatil is an Assistant Professor of the department of EEE, American International University-Bangladesh, 408/1, Kuratoli, Khilkhet, Dhaka 1229, Bangladesh. Email: abu.shatil@aiub.edu synchronous generator can be connected to a diode or operated rectifier to generate direct current and the profound portion of the rotor current with a power factor of around unity. The key disadvantages of this configuration are that the WTG's motor cannot be started, and its rotor current can be turbulent [3]. The primary advantage of salient pole machines is their lower manufacturing costs - particularly in applications that area and size are insignificant. To some extent, advantages just 'appear' - due to apples and pears comparisons: cylindrical rotor machines target fast-rotating applications where salient pole machines simply disintegrate due to mechanical stress [4]. One workaround is the claw pole generator, which trades mechanical stability for efficiency. They are more important than cylindrical machines with equivalent performance when it comes to salient pole machines [5-6]. A greater moment of inertia aids in demonstrating equilibrium in this case. With equal moments of inertia, this advantage vanishes.

The wind energy market is gradually shifting towards PMSG due to its direct drive feature and wide operating range [7]. For the direct drive PMSG low speed high torque generator with full scale converter is used. Low speed operation and the absence of gear box offers lower maintenance expenses and easily manageable and controllable features though the manufacturing cost is higher. The rise in temperature gradually decreases the flux density of the permanent magnets. To operate efficiently, complex control strategy with expensive power converter system is a requirement for PMSG wind turbines [8-9].

The paper is divided into the following sections. Section II presents the mathematical model of wind turbine and generators. Section III briefly describes PMSG WECS and comparative discussion about non salient pole and salient pole rotor. Simulation analysis is discussed in section IV. And section V summarizes and concludes the paper.

\section{PMSG WIND TURBINE MODEL}

\subsection{Aerodynamic model}

Wind turbine is used to convert the kinetic energy of the wind to mechanical power. The wind speed sequence consists of four components [8].

$$
v_{w}(t)=v_{a}(t)+v_{r}(t)+v_{g}(t)+v_{t}(t)
$$


Here, $v_{a}$ is the constant wind component, $v_{r}$ is the ramp wind component, $v_{g}=$ gust wind component, $v_{a}=$ turbulence or base noise wind component. All of them are in $\mathrm{m} / \mathrm{s}$. The wind power extracted from the wind can be expressed as [10-11]:

$$
P_{m}=\frac{1}{2} \rho \pi R^{2} C_{p}(\lambda, \beta) v^{3}{ }_{w}
$$

here, $P_{m}$ is the power extracted from the wind, $\rho=$ air density $\left(\mathrm{kg} / \mathrm{m}^{3}\right), R=$ Blade radius $(\mathrm{m}), v=$ wind speed $(\mathrm{m} / \mathrm{s})$, $C_{p}(\lambda, \beta)=$ Power coefficient of the wind turbine, $\beta=$ Blade pitch angle (deg), $\lambda=$ Tip speed ratio. The function of $C_{p}$ in terms of tip speed ratio $(\lambda)$, and blade pitch angle $(\beta)$ can be expressed as:

$$
C_{p}(\lambda, \beta)=0.5176\left[\left(\frac{116}{\lambda_{i}}-0.4 \beta-5\right) e^{-\frac{21}{\lambda_{i}}}+0.0068 \lambda\right]
$$

With,

$$
\frac{1}{\lambda_{i}}=\left(\frac{1}{\lambda+0.08 \beta}\right)-\left(\frac{0.035}{\beta^{3}}\right)
$$

Here, $\beta$ is the pitch angle (deg), which is the angle between rotational plane and blade cross section. $\lambda=$ tip speed ratio which can be defined as,$\lambda=\frac{\omega R}{v_{w}}$. Here, $R=$ rotor radius $(\mathrm{m})$, $\omega=$ angular velocity of rotor $(\mathrm{rad} / \mathrm{sec})$ and $v_{w}=$ wind speed $(\mathrm{m} / \mathrm{s})$. Fig. 1 shows the relationship between turbine power and speed. It is shown that power captured by the wind turbine is maximum at a particular rotational speed while pitch angle is kept constant [12].

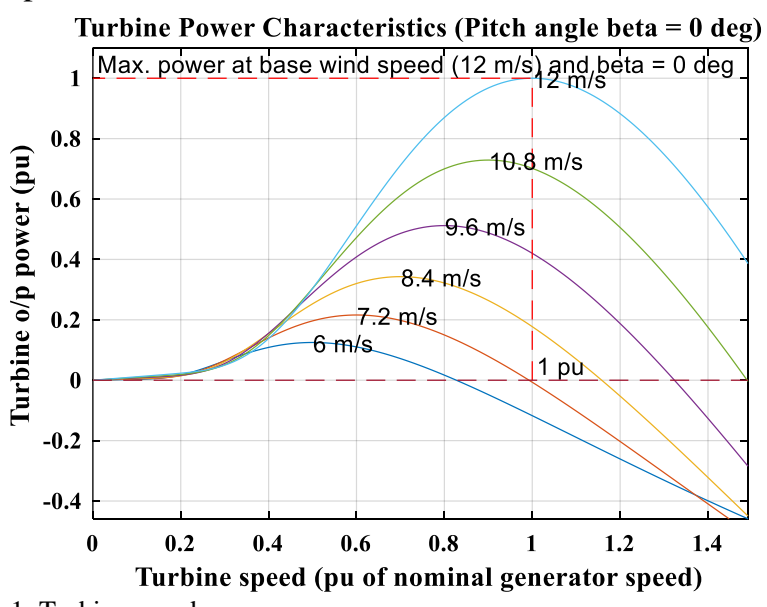

Fig. 1: Turbine speed power curve.

The maximum value of $C_{p}\left(C_{p \max }=0.48\right)$ is achieved for $\beta=0$ degree and $\lambda=8.1$. This is the nominal value for $\lambda$. $C_{\text {pmax }}=0.48$, means that the power extracted from wind wind turbine is less than the Betz's limit which is $59.3 \%$. It is because of the aerodynamic losses that depends on rotor construction such as number or shape of blade, weight, stiffness etc.

\subsection{Mathematical model of PMSG}

The PMSG mathematical model is expressed in rotating reference frame $(d q)$ frame. All the quantities in the rotor reference frame are referred to the stator. The $d$ axis and $q$ axis current equations can be defined as [12-14]:

$$
\begin{aligned}
& \frac{d}{d t} i_{s d}=\frac{1}{L_{s d}} v_{s d}-\frac{R}{L_{s d}} i_{s d}+\frac{L_{s q}}{L_{s d}} \omega_{m} i_{s q} \\
& \frac{d}{d t} i_{s q}=\frac{1}{L_{s q}} v_{s q}-\frac{R}{L_{s q}} i_{s q}-\frac{L_{s d}}{L_{s q}} P \omega_{m} i_{s d}-\frac{\lambda P \omega_{m}}{L_{s q}}
\end{aligned}
$$

The equation of electromagnetic torque is,

$$
T_{e}=1.5 P\left[\lambda i_{s q}+\left(L_{s d}-L_{s q}\right) i_{s d} i_{s q}\right]
$$

The difference between salient pole rotor and non-salient pole (round) rotor is that there is no variation in phase inductance in round rotor.

$$
L_{s q}=L_{s d}=\frac{L_{p h}}{2}
$$

But for the salient pole rotor the $d q$ inductance would be,

$\begin{aligned} L_{s d} & =\frac{L_{p h(\max )}}{2} \\ L_{s q} & =\frac{L_{p h(\min )}}{2}\end{aligned}$

Here, $L_{p h(\max )}$ and $L_{p h(\min )}$ are maximum $d$ axis inductance and minimum $q$ axis inductance respectively. Active and reactive power equations are:

$$
\begin{aligned}
& P_{s}=V_{s d} i_{s d}+V_{s q} i_{s q} \\
& Q_{s}=V_{s q} i_{s d}-V_{s d} i_{s q}
\end{aligned}
$$

Here, $i_{s q}$ and $i_{s d}$ are $q$ and $d$ axis currents respectively. $v_{s q}$ and $v_{s d}$ are $q$ and $d$ axis voltages respectively. $L_{s q}$ and $L_{s d}$ are $q$ and $d$ axis inductances respectively. $\omega_{m}=$ angular velocity of the rotor; $R=$ resistance of the stator winding; $P=$ no. of pole pairs; $T_{e}=$ electromagnetic torque and $\lambda=$ amplitude of the flux induced by the permanent magnets of the rotor in the stator phases.

\subsection{Pitch angle controller}

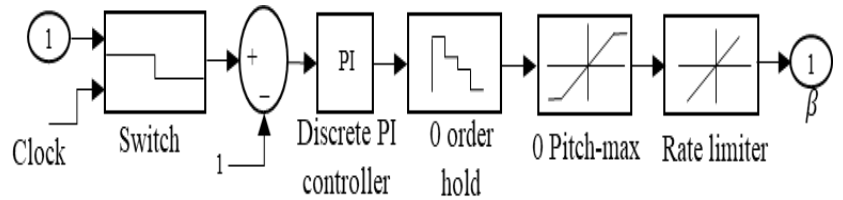

Fig. 2: VSWT pitch angle $(\beta)$ controller.

Aerodynamic control system is necessary to control mechanical power. Pitch angle controller generally works to change the blade angle that prevents the rotor speed from exceeding the rated speed. It also protects the generator from overloading at high wind speed [15-16]. In Fig. 2 input generator speed is compared with the nominal value through PI controller which is used to manage the tracking error.

\section{SYSTEM DESCRIPTION}

\subsection{System description of VS-PMSG wind turbine}

The variable speed PMSG wind turbine is connected to the AC grid through a back to back (AC-DC-AC) full power converter [17]. The converter system is a bidirectional power converter that consists of IGBT based pulse width modulated (PWM) VSCs connected through DC link as in Fig. 3. The complete system consists of wind turbine with drive train models, PMSG, generator side controller and grid side controller. Both of the converters are built by IGBT. They are controlled by generator side and grid side controller. The generator side controller is associated to the stator terminal and the grid side controller is connected to the grid system through step up transformer. The generator side controller transforms the three phase AC voltage generated by PMSG to DC voltage. And the grid side controller transforms the DC voltage into three phase $\mathrm{AC}$ voltage of the grid frequency. 


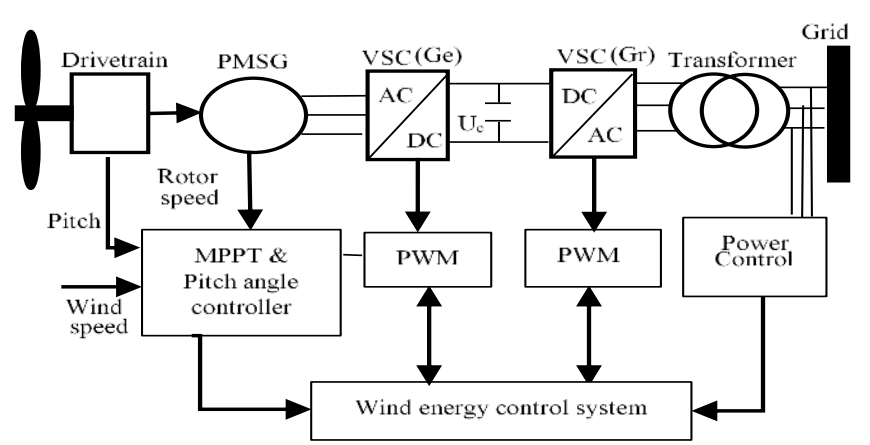

Fig. 3: General structure of the PMSG WECS.

Multipole PMSG both the non-salient or round pole rotor and salient pole rotor has been considered for the system. Parameters considered for the system is given in Table I. The PMSG is used to convert the mechanical energy extracted by the wind turbine into electricity. As the generator side and grid side is coupled through the converter, so it is possible to keep the grid side frequency constant while the change in wind speed varies the generator electrical frequency. This process makes variable speed operation possible. Power converters filter out harmonics thus reducing flicker level which improves power quality and keep it smooth. The capacitor that is in between the inverter and rectifier is called DC link capacitor. Decoupling the control of the two converter is possible because of it [18-19].

Matlab/Simulink model of the PMSG WECS, VSC of the generator side and VSC of the converter side is illustrated in Fig. 4(a), (b) and (c) respectively. VSC_Ge_Reg and VSC_Gr_Reg block contains the reference values for simulation. The value of proportional gain $(\mathrm{Kp})$, integral gain $\left(\mathrm{K}_{\mathrm{i}}\right)$ and derivative gain $\left(\mathrm{K}_{\mathrm{d}}\right)$ are 180,3200 and 1 respectively. VSC_Ge_Reg also contains rotating speed controller.

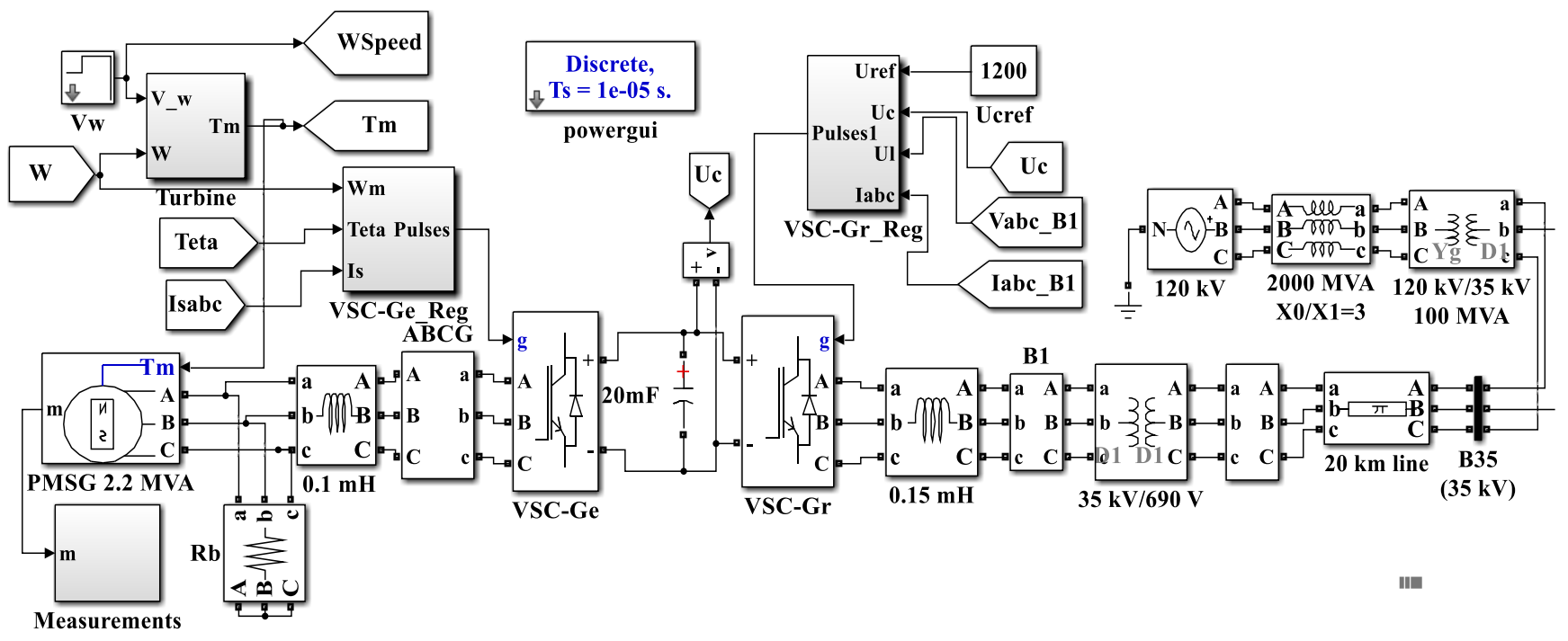

(a)

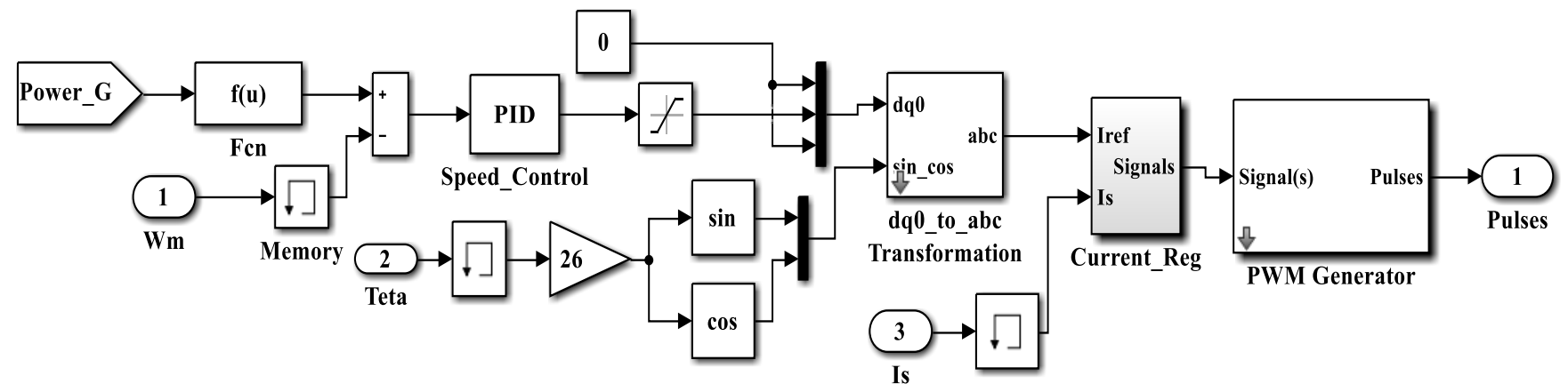

(b) 


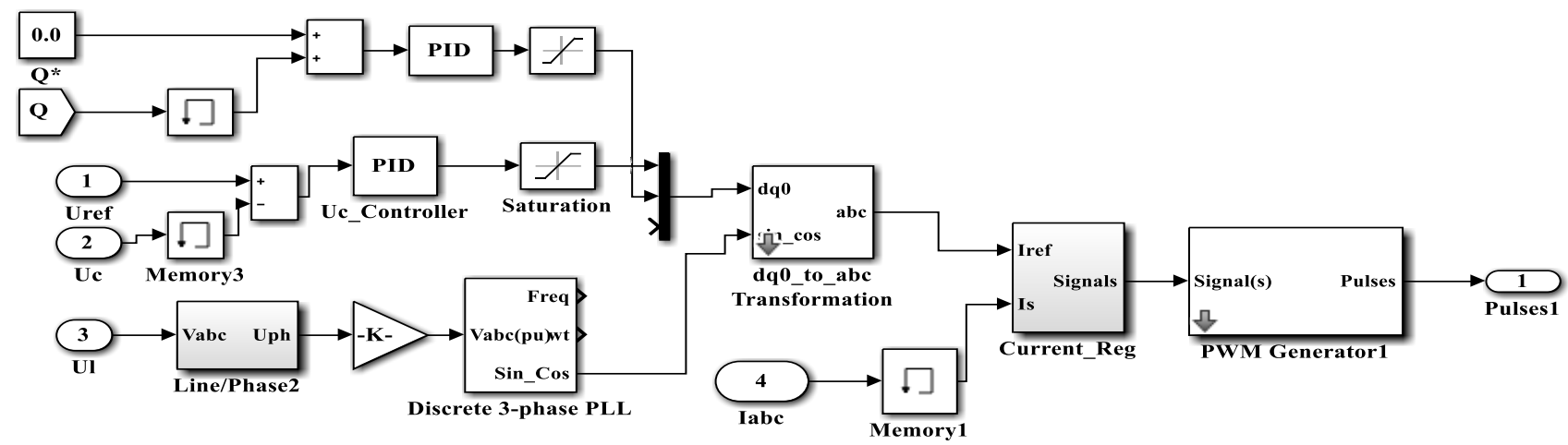

(c)

Fig. 4: Matlab/Simulink design of the (a) PMSG wind turbine system, (b) Generator side voltage source converter and (c) Grid side voltage source converter

The DC link voltage voltage $\left(U_{c}\right)$ is kept constant by controlling the grid side converter. It is achieved by supplying active power to the grid and controlling reactive power flow to the system. Even in low wind speed it is possible to extract power by controlling pitch angle controller. It also protects the system from wind gust [20].

\subsection{Non-salient (round) pole rotor vs salient pole rotor}

Self-excitation is a key feature of PMSG. The rotor of PMSG contains the magnets that creates the rotor magnetic field of the generator. Non-salient pole rotors and salient pole rotors are the two rotor types in PMSG. Each of these types have their own benefits and downsides. The main difference between round pole rotor and salient pole rotor is the air gap between the stator and rotor. Round pole rotor generators have uniform air gap. Because of that the reluctance of the magnetic path is same in all direction. As a result reactance $\left(X_{S}\right)$ remains same. The air gap of salient pole rotor is non uniform. So, reactance also varies with the rotor position. In the case of round pole generator only $d$ axis of geometric symmetry exists but salient pole machines have both $d$ axis and $q$ axis of geometric symmetry. According to the two reaction theory by Blondel because of the non-uniform air gap reluctance on the $q$ axis $\left(X_{q}\right)$ is greater than reluctance on the $d$ axis $\left(X_{d}\right)$ [19]. Non-salient or round pole rotor machines are used in high speed applications. They have advantages such as robust construction, less windage loss. The number of pole pairs are higher compared to the salient pole rotors generators. Salient pole rotor generators are more suitable for low speed applications [22-23].

\section{SIMULATION ANALYSIS}

The complete variable speed WECS was designed and simulated by Matlab/Simulink using the parameters given in Table 1. The surface magnet generator (SPMSG) is utilized in the Simulink model of non-salient pole PMSG, in which $L_{d}=$ $L_{\mathrm{q}}$; therefore, the generator current component $I_{\mathrm{q}}$ is defined with the wanted torque, and the component $I_{\mathrm{d}}$ is equal to zero. The model of wind turbine salient pole PMSG is a copy of PMSG non-salient pole except for the fact that instead of SPMSG, the interior permanent magnet synchronous generator (IPMSG) is utilized where $\left(L_{\mathrm{d}} \neq L_{\mathrm{q}}\right.$. The blocks which compute the reference are added in the subsystem VSCGe_Reg in the
WECS model. There, Gain1 block recalculates the actual reference for $i_{s q}$ into the relative unit. Fen1 block solves the quadratic equations and the block Gain 2 carries out the calculations inverse to the block Gain1. The power, voltage and rotating speed are kept same in both the cases of the generators. In the case of IPMSG number of pole pairs is higher which reduces rotor flux. Fig. 5 shows the wind speed variation. Under nominal condition (wind speed $12 \mathrm{~m} / \mathrm{s}$ ) with the increase in wind speed upto $15 \mathrm{~m} / \mathrm{s}$ at $t=7 \mathrm{~s}$ and its abatement to $7 \mathrm{~m} / \mathrm{s}$ at $t=20 \mathrm{~s}$. Fig. 6 to Fig. 8 shows the rotor speed, pitch angle and torque changes respectively. It can be seen that with the increase in wind speed the angular velocity of the rotor speed of PMSG also increases. The speed limit is obtained with the pitch angle variation. The value of torque is negative because it is clockwise. Fig. 9 to Fig. 11 shows the simulation result of PMSG non-salient pole and salient pole generator voltage, current and power respectively. Nominal current of PMSG can be determined as:

$$
I_{n}=\frac{\sqrt{2} \times 2.2 \times 10^{6}}{\frac{690}{\sqrt{3}}}=2606 \mathrm{~A}
$$

Here, Transparent power $S=2.2$ MVA under the nominal voltage of $690 \mathrm{~V}$ and frequency of $9.75 \mathrm{~Hz}$. Nominal rotating speed of non-salient pole and salient pole generator is, $\omega_{n}=$ $2 \times \pi \times(9.75 / 26)=2.355 \mathrm{rad} / \mathrm{s}$ and $\omega_{n}=2 \times \pi \times$ $(9.75 / 30)=2.041 \mathrm{rad} / \mathrm{s}$ respectively.

Here, 26 and 30 are the number of pole pairs taken from TABLE I. And the nominal torque of non-salient pole and salient pole rotor is,

$$
\begin{aligned}
& T_{e n}=2.2 \times \frac{10^{6}}{2.355}=934.2 \mathrm{kNm} \text { and } \\
& T_{e n}=2.2 \times \frac{10^{6}}{2.041}=1077.9 \mathrm{kNm}
\end{aligned}
$$

In order to have minimum IPMSG current with same torque current component $I_{d}$ should be controlled. The turbine has the power of $2 \mathrm{MW}$ at the base wind speed of $12 \mathrm{~m} / \mathrm{s}$ in both the system. Back to back VSCs are connected utilizing IGBT and PWM with the frequency of $2160 \mathrm{~Hz}$ in both system. VSC-Ge control system contains rotating speed controller. The reference speed can be defined as, $\omega_{r}=K_{m} \sqrt[3]{P_{g}}$. Here, $P_{g}$ is the measured PMSG power and $K_{m}$ is the coefficient which depends on accepted units and on the turbine parameters. In this case under consideration in pu $K_{m}=1$. The value is optimal if $P_{g}$ is equal to the optimal value at the given wind speed. During steady state operation in both of the cases 
reactive power at generator side is kept nearly zero. If the wind speed rises, $P \mathrm{~g}$ also increases. The rotating speed increases until it reaches the value that corresponds to the maximum at the new wind speed. Fig. 11 shows the simulation result of DC link voltage of non-salient pole and salient pole PMSG. It is produced by grid side converter and the phase voltage fed to the grid. The value of the DC link voltage is around $1200 \mathrm{~V}$. It remains constant and well controlled in both cases.

Fig. 13 shows the wave forms of active and reactive power of grid side non-salient pole and salient pole rotor PMSG respectively. Changes in wind speed can be resulted in the fluctuation of the power components. It can be seen that total harmonic distortion is not more than $2 \%$ in the network current. Though both of the system contains converters that are rated $100 \%$, it can be seen that active power injected to the grid by salient pole PMSG WECS is smother compared to the other.

TABLE I

Parameters of simulated PMSG wind turbine.

\begin{tabular}{|c|c|c|c|}
\hline Parameters & \multicolumn{2}{|c|}{ Value } & Unit \\
\hline Rated power & \multicolumn{2}{|c|}{2} & $\mathrm{MW}$ \\
\hline Frequency & \multicolumn{2}{|c|}{50} & $\mathrm{~Hz}$ \\
\hline DC link capacitance & \multicolumn{2}{|c|}{20} & $\mathrm{mF}$ \\
\hline Rated speed & \multicolumn{2}{|c|}{12} & $\mathrm{~m} / \mathrm{s}$ \\
\hline Rated voltage & \multicolumn{2}{|c|}{690} & $\mathrm{~V}$ \\
\hline $\begin{array}{c}\text { Non } \\
\text { salient }\end{array}$ & Salient & \\
\hline Pole pairs & 26 & 30 & $\mathrm{~m} \Omega$ \\
\hline $\begin{array}{c}\text { Stator phase } \\
\text { resistance }\end{array}$ & 0.78 & 0.8 & $\mathrm{mH}$ \\
\hline $\begin{array}{c}\text { Armature } \\
\text { inductance }\end{array}$ & 1.57 & $\begin{array}{c}\mathrm{L}_{\mathrm{d}}=1.5 ; \\
\mathrm{L}_{\mathrm{q}}=2.6\end{array}$ & $\mathrm{~Wb}$ \\
\hline Flux linkage & 9.18 & 7.9 & $\mathrm{~Wb}$ \\
\hline
\end{tabular}

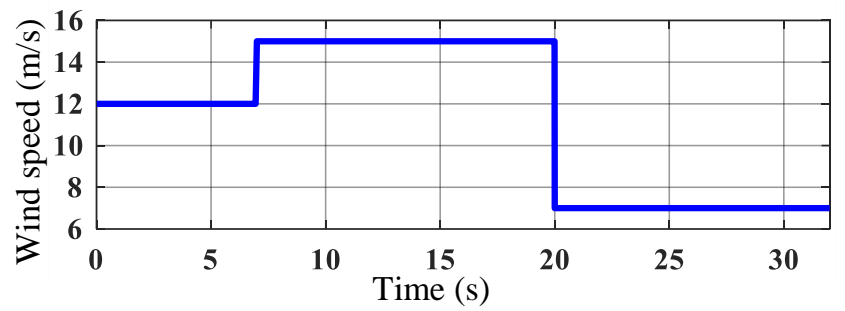

Fig. 5: Variation of wind speed.

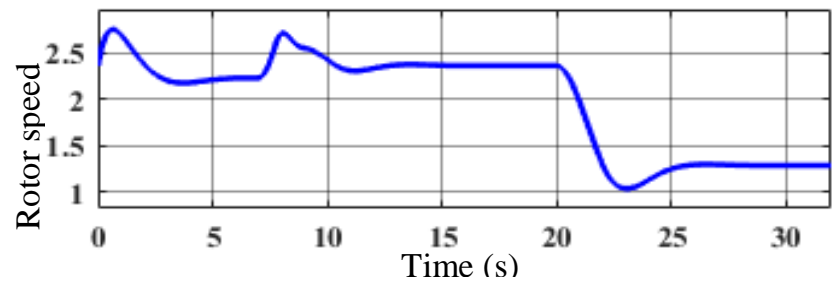

Fig. 6: Rotor speed.

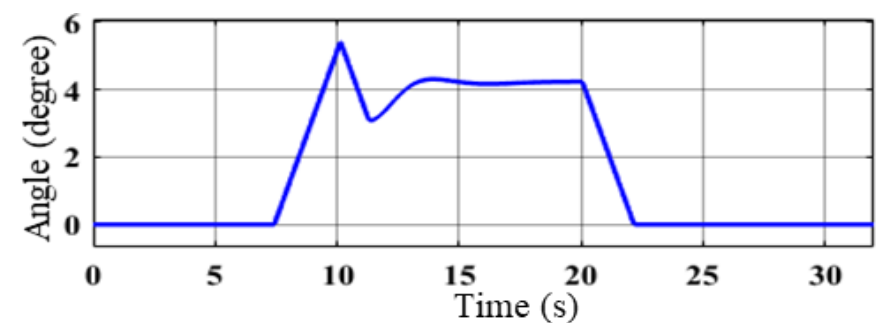

Fig. 7: Pitch angle.

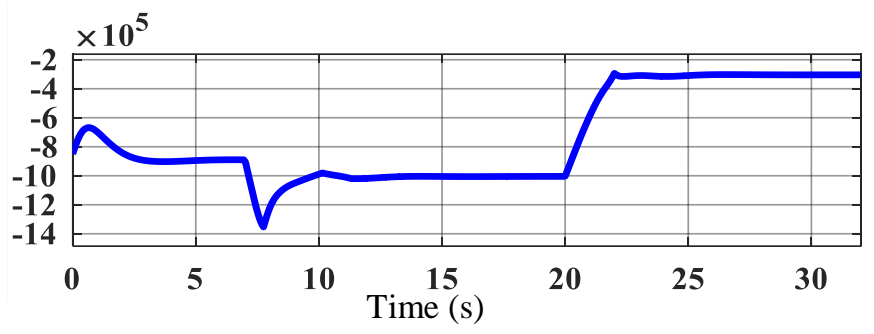

Fig. 8: Wind turbine torque (Nm).

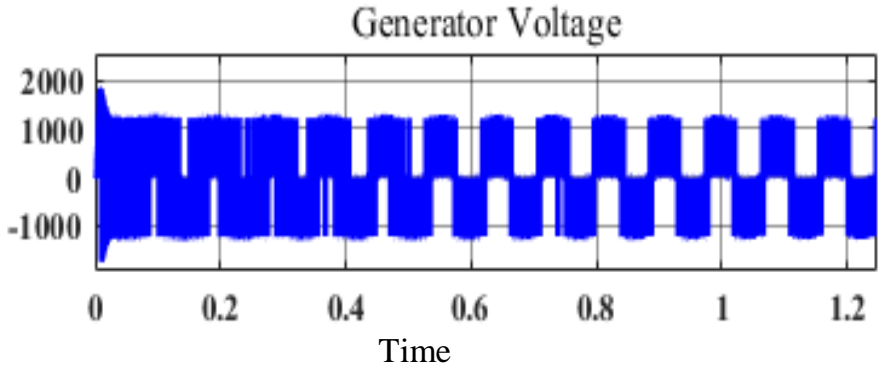

(a)

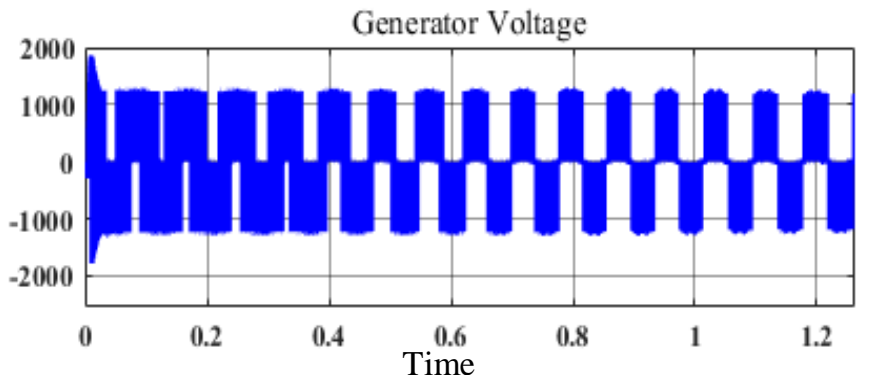

(b)

Fig. 9: Generator side voltage of (a) non-salient pole PMSG, (b) salient pole PMSG.

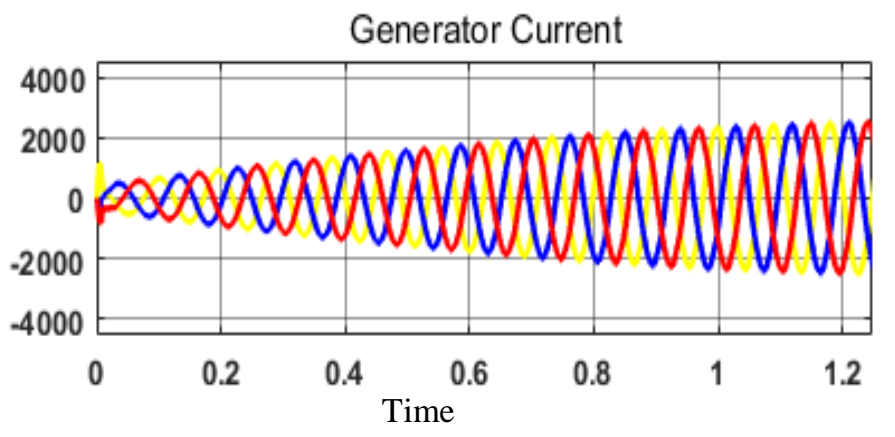

(a) 
Generator Current

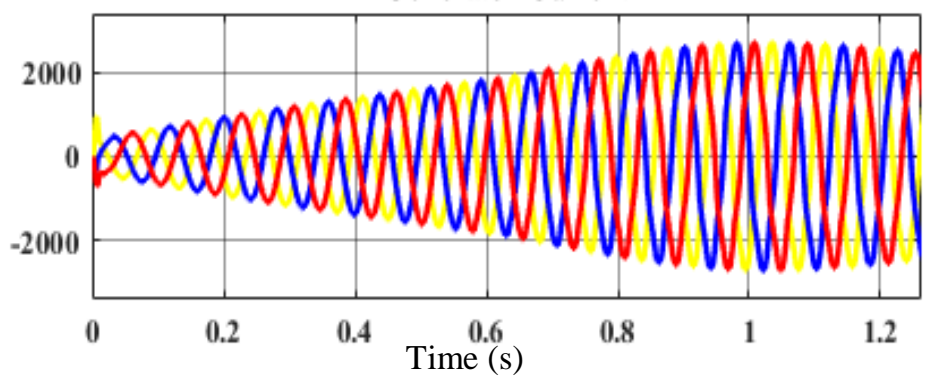

(b)

Fig. 10: Generator side current of (a) non-salient pole PMSG, (b) salient pole PMSG.

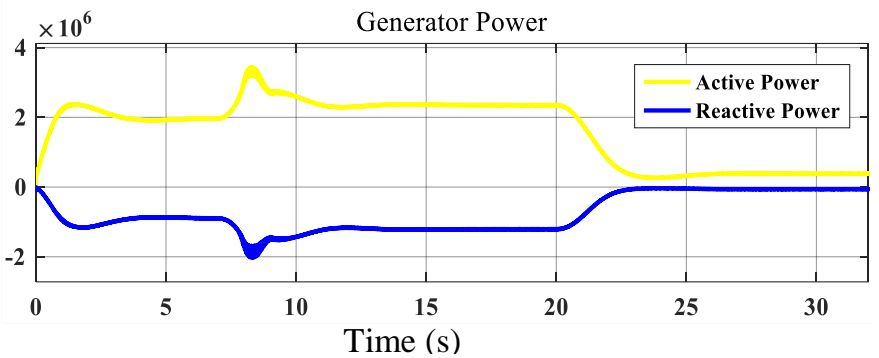

(a)

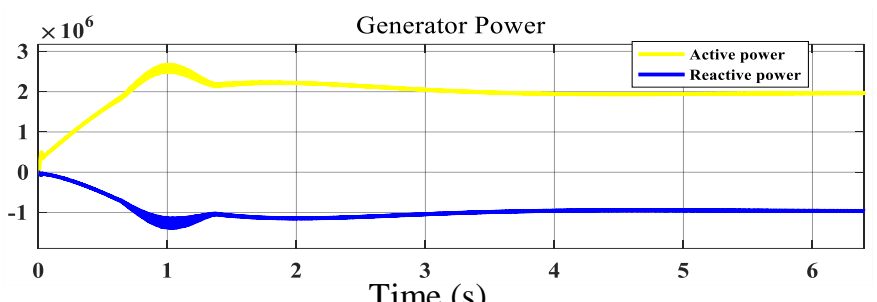

(b)

Fig. 11: Active and reactive power of generator side (a) non-salient pole PMSG, (b) salient pole PMSG.

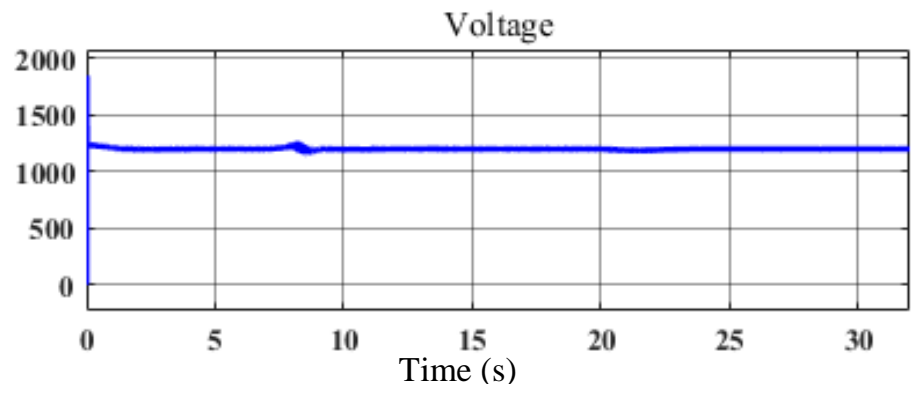

(a)

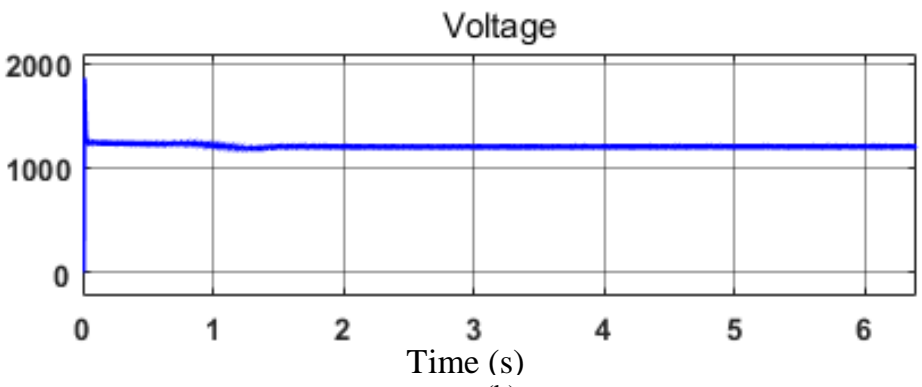

(b)

Fig. 12: DC link voltage of (a) non-salient pole PMSG, (b) salient pole PMSG.

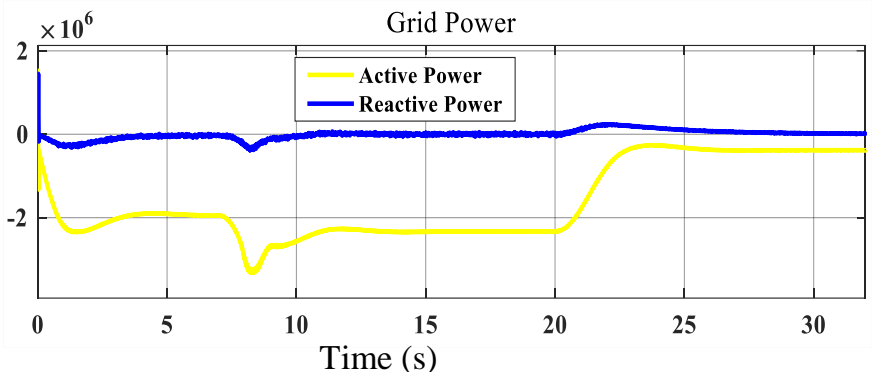

(a)

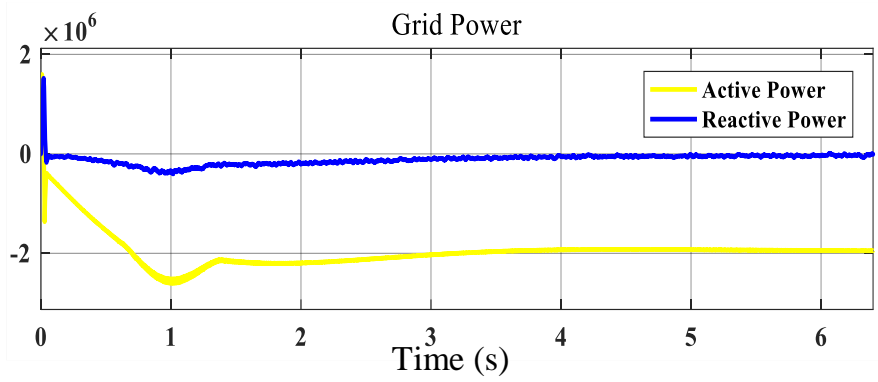

(b)

Fig. 13: Active and reactive power of grid side (a) non-salient pole PMSG, (b) salient pole PMSG.

\section{CONCLUSIONS}

This paper presents the model of a VS WECS using PMSG non-salient pole and salient pole rotor. The differences between these two types of generators in WT system and their impacts on the output have been discussed. The objective of this study is to compare the performance and give an overview of these two rotor types of grid connected generators. Non salient pole rotor PMSG offers robust structure with high speed performance and high power quality whereas salient pole rotor PMSG offers low speed performance with comparatively low cost. Though the power quality is higher in non-salient pole rotor PMSG but the power generation is limited due to only magnetic torque. Salient pole rotor PMSG have reluctance torque and magnetic torque which helps it to generate high power. It offers smooth power flow even in low wind speed. If issues such as power quality, reliability and efficiency are considered then direct drive PMSG non salient pole wind turbine offers better solution.

\section{REFERENCES}

[1] H. Polinder, J. A. Ferreira, B. B. Jensen, A. B. Abrahamsen, K. Atallah and R. A. McMahon, "Trends in Wind Turbine Generator Systems," in IEEE Journal of Emerging and Selected Topics in Power Electronics, vol. 1, no. 3, pp. 174-185, Sept. 2013, doi: 10.1109/JESTPE.2013.2280428.

[2] M. Dubois, "Optimized permanent magnet generator topologies for direct drive wind turbines," Electr. Eng. Dept., Delft Univ. Technol., Delft, The Netherlands, 2004

[3] R. G. Hernandez and R. G. Ramirez, "Modeling and Control of a Wind Turbine Synchronous Generator," 2011 IEEE Electronics, Robotics and Automotive Mechanics Conference, 2011, pp. 222-227, doi: 10.1109/CERMA.2011.42.

[4] G. Kömürgöz and T. Gündogdu, "Comparison of salient pole and Permanent Magnet Synchronous Machines designed for wind turbines," 2012 IEEE Power Electronics and Machines in Wind Applications, 2012, pp. 1-5, doi: 10.1109/PEMWA.2012.6316381.

[5] F. Jurca, C. Martis and K. Biro, "Comparative analysis of the claw-pole rotor dimensions influence on the performances of a claw -pole generator for wind applications," 2009 International Conference on 
Clean Electrical Power, 2009, pp. 715-720, doi: 10.1109/ICCEP.2009.5211975.

[6] F. Lorenz, R. Werner and M. Föse, "Claw pole generator with adapted efficiency curve for small scale wind turbines," 2018 IEEE International Conference on Industrial Technology (ICIT), 2018, pp. 346-351, doi: 10.1109/ICIT.2018.8352202.

[7] Nityanand and A. K. Pandey, "Performance Analysis of PMSG Wind Turbine at Variable Wind Speed," 2018 5th IEEE Uttar Pradesh Section International Conference on Electrical, Electronics and Computer Engineering (UPCON), Gorakhpur, 2018, pp. 1-6, doi: 10.1109/UPCON.2018.8597081.

[8] L. Soderlund, J. -. Eriksson, J. Salonen, H. Vihriala and R. Perala, "A permanent-magnet generator for wind power applications," in IEEE Transactions on Magnetics, vol. 32, no. 4, pp. 2389-2392, July 1996, doi: $10.1109 / 20.511354$.

[9] Jain, Anjana \& Shankar, S. \& Venkataraman, Vanitha. (2018). Power Generation Using Permanent Magnet Synchronous Generator (PMSG) Based Variable Speed Wind Energy Conversion System (WECS): An Overview .Journal of Green Engineering 7.477-504.10.13052/jge19044720.742.

[10] K. Elkington, J.G. (Han) Slootweg, M. Ghandhari and W. L. Kling, "Reduced-order modelling of wind turbines," in Wind Power in Power Systems, $2^{\text {nd }}$ ed. T. Ackermann, Ed. United Kingdom: John Wiley \& Sons Ltd, 2012, ch 36, pp. 821-845.

[11] Junfei Chen, Hongbin Wu, Ming Sun, Weinan Jiang, Liang Cai and Caiyun Guo, "Modeling and simulation of directly driven wind turbine with permanent magnet synchronous generator," IEEE PES Innovative Smart Grid Technologies, Tianjin, 2012, pp. 1-5, doi: 10.1109/ISGTAsia.2012.6303300.

[12] Wang, Chia-Nan \& Lin, Wen-Chang \& Le, Khoa. (2014). Modelling of a PMSG Wind Turbine with Autonomous Control. Mathematical Problems in Engineering. 2014. 1-9. 10.1155/2014/856173.

[13] Junfei Chen, Hongbin Wu, Ming Sun, Weinan Jiang, Liang Cai and Caiyun Guo, "Modeling and simulation of directly driven wind turbine with permanent magnet synchronous generator," IEEE PES Innovative Smart Grid Technologies, 2012, pp. 1-5, doi: 10.1109/ISGTAsia.2012.6303300.

[14] Li, Shuhui \& Haskew, Timothy \& Xu, Ling. (2010). Conventional and novel control designs for direct driven PMSG wind turbines. Electric Power Systems Research. 80. 328-338. 10.1016/j.epsr.2009.09.016.

[15] Tazi, Khadija \& Abbou, Fouad \& Abdi, F. (2019). Performance analysis of micro-grid designs with local PMSG wind turbines. Energy Systems. 1-33. 10.1007/s12667-019-00334-2.

[16] Hazari, Md. Rifat \& Mannan, Mohammad \& Muyeen, S M \& Umemura, Atsushi \& Takahashi, Rion \& Tamura, Junji. (2017). Stability Augmentation of a Grid-Connected Wind Farm by Fuzzy-LogicControlled DFIG-Based Wind Turbines. Applied Sciences. 8. 20. 10.3390/app8010020.

[17] Errami, Y. \& Ouassaid, Mohammed \& Maaroufi, Mohamed. (2013). Control of a PMSG based Wind Energy Generation System for Power Maximization and Grid Fault Conditions. Energy Procedia. 42. 220-229. 10.1016/j.egypro.2013.11.022.

[18] A. Rolan, A. Luna, G. Vazquez, D. Aguilar and G. Azevedo, "Modeling of a variable speed wind turbine with a Permanent Magnet Synchronous Generator," 2009 IEEE International Symposium on Industrial Electronics, Seoul, 2009, pp. 734-739, doi: 10.1109/ISIE.2009.5218120.

[19] H. Knudsen and J. N. Nielsen, "Introduction to the Modelling of Wind Turbines," in Wind Power in Power Systems, $2^{\text {nd }}$ ed. T. Ackermann, Ed. United Kingdom: John Wiley \& Sons Ltd, 2012, ch 34, pp. 769-796.

[20] M. Q. Duong, K. H. Le, F. Grimaccia, S. Leva, M. Mussetta and R. E. Zich, "Comparison of power quality in different grid-integrated wind turbines," 2014 16th International Conference on Harmonics and Quality of Power (ICHQP), Bucharest, 2014, pp. 448-452, doi: 10.1109/ICHQP.2014.6842779.

[21] B. L. Theraja, A. K. Theraja, "Alternators," in A Textbook of Electrical Technology. India: S. Chand and Company Limited, 2012, ch. 37, pp. 1401-1488.

[22] H. Chen, R. Qu, J. Li and B. Zhao, "Comparison of interior and surface permanent magnet machines with fractional slot concentrated windings for direct-drive wind generators," 2014 17th International Conference on Electrical Machines and Systems (ICEMS), Hangzhou, 2014, pp. 26122617, doi: 10.1109/ICEMS.2014.7013942.

[23] A. D. Hansen, "Generators and Power Electronics for Wind Turbines," in Wind Power in Power Systems, $2^{\text {nd }}$ ed. T. Ackermann, Ed. United Kingdom: John Wiley \& Sons Ltd, 2012, ch 5, pp. 73-102

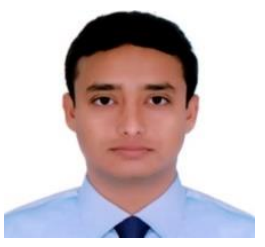

S. M. Mehedi Hasan received his B.Sc. Engg. Degree in Electrical and Electronic Engineering (EEE) from American International UniversityBangladesh (AIUB) in 2018. Currently he is pursuing his master's degree at American International University-Bangladesh (AIUB). His research interest is focused on Renewable Energy Technology.

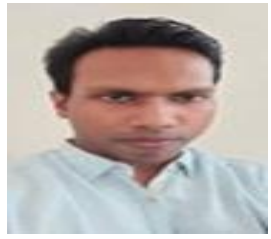

Abu Hena MD Shatil is an Assistant Professor of Electrical and Electronic Engineering (EEE) department at American International University Bangladesh (AIUB). His work focuses specifically on the Energy modelling and their impact on society. He obtained Postgraduate degree in Electrical Energy System from Cardiff University, UK. 